\title{
As seqüências qu- e gu- mais vogal
}

\author{
Hildo Honório do Couto \\ Universidade de Brasilia
}

\section{Abstract}

The aim of this paper is to discuss the possible interpretations of the high back vowel $[\mathrm{w}]$ preceded by [k] or [g] and followed by another vowel. Some phonologists interpret $[\mathrm{kw}]$ and $[\mathrm{gw}]$ as the labialized velars $/ \mathrm{k}^{\mathrm{w}} /$ and $/ \mathrm{g} /$, respectively. In the framework of the present-day preference for principles instead of rules, I argue that the best interpretation for these groups would be as $/ \mathrm{k} /$ and $\mathrm{lg} /$ followed by a diphthong. However, both interpretations have advantages and disadvantages. 


\section{INTRODUÇÃO}
A seqüências de sons representadas graficamente por $q u$ - $\mathrm{e}$ $g u$-são grupos de fonemas suigeneris na língua portuguesa. 1 são os únicos casos em que ocorre a semivogal alta posterior /w/ precedida de consoante e seguida de outra vogal em uma única sílaba fonética, como nos exemplos de (1).

$\begin{array}{ll}\text { (1) (a) iníqua } & \text { (b) ambígua } \\ \text { Pariqüera, eqüestre } & \text { Anangüera } \\ \text { liqüefeito } & \text { bangüê } \\ \text { iniqüidade } & \text { exigüidade } \\ \text { quórum, quiproquó } & ? \\ \text { apropínquo } & \text { exíguo' }^{1}\end{array}$

Como se devem interpretar fonologicamente as seqüências [kwV] e [gwV]? Devido ao caráter excepcional dessas seqüências, alguns autores sugeriram que fossem interpretadas como $/ \mathrm{k}^{\mathrm{w}} / \mathrm{e}$ $/ \mathrm{g} /$, não como uma seqüência constituída de uma consoante velar e uma semivogal ou uma vogal alta posterior. Até onde pude investigar, o primeiro autor a propor essa solução foi Pardal (1977). Martins (1988:117-118) aparentemente subscreve sua intepretação, reproduzindo-a.

Aqui no Brasil, parece ter sido Leda Bisol (cf. Bisol 1989) a primeira fonóloga a sugerir uma solução parecida. Uma outra autora que a defende com conviç̧ão é Janete Melasso Garcia (cf. Garcia 1989), em uma dissertação de mestrado em que compara as estruturas silábicas do latim e do português-padrão. Para a primeira autora, não se trataria de mais dois fonemas no inventário fonemático 
da língua portuguesa. Tratar-se-ia de uma "unidade monofonemática" que estaria no léxico (Bisol 1989: 216). Ela acrescenta que essa "unidade monofonemática, no sentido de Troubetzkoy, não aumenta o número de fonemas da língua, pois está apenas no léxico, indicando as poucas palavras que preservam o grupo latino. $O$ glide, neste caso, situa-se no 'onset' não ramificado", como em (2), reproduzido da representação (42) de Bisol (1989: 217).

$$
\begin{aligned}
& / \mathrm{k}^{\mathrm{w}} \mathrm{a} 1 / \\
& 11 \\
& \mathrm{O} \quad \mathrm{R} \quad(\mathrm{O}=\text { onset, aclive; } \mathrm{R}=\text { rima) } \\
& 1 / 1 \\
& \mathrm{k}^{\mathrm{w}} \text { a } \quad 1
\end{aligned}
$$

Como se vê, o essencial da argumentação de Bisol é basicamente sincrônico. Para Garcia, no entanto, a razão para se postularem mais dois fonemas na língua portuguesa é de ordem sobretudo diacrônica (Garcia 1989: 10-14, 85), como veremos mais abaixo.

Pois bem, o que pretendo fazer neste artigo é mostrar que a solução proposta por Bisol (1989) ${ }^{2}$ e por Garcia (1989) não é livre de problemas. Com efeito, há uma regra fonológica que parece invalidar os argumentos da primeira. Em seguida, argumentarei no sentido de que nem precisaríamos dessa regra, pois há um princípio universal que a engloba. Quanto ao ponto de vista da segunda, de fundo diacrônico, tentarei mostrar que não é válido justamente por esse fato. Como veremos, nem suas justificativas de base sincrônica (distribucional) são válidas.

\section{PRESUMÍVEIS RAZŌES PARA DOIS SEGMENTOS LABIALIZADOS}

Em seu artigo de 1989, Leda Bisol afirma que "a proposta é que a seqüência consoante velar e glide posterior supramencionada seja 
indicada no léxico como uma unidade monofonemática $/ \mathrm{k}^{\mathrm{w}} / \mathrm{e}$ $/ \mathrm{g}^{\mathrm{w}} /$, aderindo ao seguinte princípio de Troubetzkoy:

Regle IV (1967:62): "Si une partie constitutive d'un groupe phonique potentiellement monophonématique ne peut (sublinhado meu) être interprété comme une variante combinatoire d'un phonème unique quelconque de la même langue, tout le groupe phonique peut êlre considéré comme une réalisation d'un phonème particulier" (Bisol 1989: 216).

Garcia (1989), por seu turno, começa por justificar a interpretação dos segmentos em questão como fonemas complexos (velares labializados) no latim, aduzindo argumentos não apenas da fonotática dessa língua (inclusive cle métrica) mas também de autores consagrados. Passando ao português, a autora afirma que os "chamadơs ditongos crescentes só se apresentam estáveis quando vêm precedidos de $/ \mathrm{k} / \mathrm{e} / \mathrm{g} /$ ". Isso seria uma evidência no sentido de que "deveria haver uma razão motivadora desta estabilidade. Se o único contexto que garante a estabilidade é a presença de $/ \mathrm{k} / \mathrm{e} / \mathrm{g} /$, provavelmente haveria uma ligação fônica bastante forte entre a oclusiva velar e o fonema /u/". Diante desses fatos, ela conclui que "como para o latim, proporiamos que, também para o português, se desconsidere a possibilidade do $\underline{u}$ ser elemento de ditongo crescente (...) e passemos a considerar os fonemas $/ \mathrm{k} / \mathrm{e} / \mathrm{g} /$, seguidos de $\underline{\mathrm{u}}+\mathrm{V}$, numa mesma sílaba, como fonemas oclusivos, velares-labializados".

Contrariamente a Bisol (1989: 217), que afirma que sua interpretação "não aumenta o número de fonemas da língua", Garcia (1989: 13) diz literalmente que "com esta consideração acrescentaríamos mais dois fonemas consonânticos ao quadro fonológico do português".

\section{COMENTÁRIOS}

Vejamos, em primeiro lugar, a argumentação de Bisol. A regra de Troubetzkoy que ela apresenta como uma das justificativas para 
sua interpretação monofonemática parece ficar invalidada pelo fato de que, com efeito, uma parte constitutiva dos grupos fônicos potencialmente monofonemáticos $\left[\mathrm{k}^{\mathrm{v}}\right] \mathrm{e}\left[\mathrm{g}^{\mathrm{v}}\right]$ do português pode ser interpretada como variante combinatória de um outro fonema da mesma língua. É o que está claramente formulado na regra de (3).

$$
/ \mathrm{u} / \longrightarrow[\mathrm{w}] / \mathrm{k}, \mathrm{g} \_\mathrm{V}
$$

A regra (3) afirma que o fonema /u/ vira [w] (semivogal, ou "glide" na terminologia de Bisol) quando estiver precedido de $/ \mathrm{k} / \mathrm{ou} / \mathrm{g} / \mathrm{e}$ seguido de vogal - qualquer vogal, como se pode ver em (1) acima, e não apenas /a/ e /o/, como afirma Bisol (1991: 56-57). ${ }^{3}$

A autora afirma que sua proposta não implica a introdução de mais dois fonemas na língua. Como já foi visto acima, em suas próprias palavras, a "unidade monofonemática" está apenas no léxico. ${ }^{4}$ Além disso, a própria expressão "unidade monofonemática" que a autora invoca já sugere que sua interpretação não difere muito da que introduz os dois fonemas $/ \mathrm{k}^{\mathrm{w}} / \mathrm{e} / \mathrm{k}^{\mathrm{w}} /$. Esse é o espírito da regra de Troubetzkoy a que ela recorre.

Além da regra (3), que já invalidaria uma interpretação monofonemática, temos um motivo teoricamente muito mais forte para não aceitar essa proposta. Como sabemos, a partir da década de 80, Chomsky passou a enfatizar principios (e parâmetros) em vez de regras. ${ }^{5}$ Os princípios seriam gerais, independentes de línguas específicas, contrariamente à maioria das regras, que freqüientemente só são válidas para determinada língua. Pois bem, eu gostaria cle propor um princípio universal que explica a interpretação de [kw] e [gw] em tela como as seqüências de fonema $/ \mathrm{ku} / \mathrm{e} / \mathrm{gu} /$, de modo que a regra (3) seria apenas uma de suas aplicações. Trata-se do Princípio do Dado Automático do Contexto, (PDAC), formulado em (4).

(4) Princípio do Dado Automático do Contexto (PDAC):

Tudo que é dado automaticamente pelo contexto é desprovido de valor fonológico. 
Com isso teríamos, num nível subjacente, as seqüências de fonemas $/ \mathrm{kuV} / \mathrm{e} / \mathrm{guV} /$ que, com a atuação do princípio PDAC, virariam [kwV] e [gwV]. Isso porque, como fica claro através da regra (3), a semivocalidade (ou semiconsonantalidade, não importa) de [w] neste caso é dada automaticamente pelo contexto.

O princípio (4) já era corrente, explícita ou implicitamente, entre os fonólogos estruturalistas, como é o caso de Martinet, Troubetzkoy, Pike e outros. Em nossa época, em que a tendência teórica é valorizar princípios - e representações, no caso específico da fonologia que, não obstante, tem uma certa independência em relação à sintaxe -, ele adquire uma importância maior ainda. A fonóloga Leda Bisol foi das primeiras, se não a primeira, a tentar fazer uso de princípios em vez de regras na análise fonológica (cf. Bisol 1995).

As motivações de Garcia (1989) são, em primeiro lugar, o já mencionado fato de $/ \mathrm{k}^{\mathrm{w}} / \mathrm{e} / \mathrm{g}^{\mathrm{w}} /$ terem sido propostos como monofonemáticos em latim - e o português provém do latim, é uma das variedades "do latim de hoje" (c.p.). Em segundo lugar, a idéia de que a interpretação bifonemática impliçaria o surgimento de ditongos crescentes e de tritongos, além da possilibidade de $/ \mathrm{k}^{w}, \mathrm{~g}^{\mathrm{w}} /$ poderem "ocupar a posição de consoante simples" como em "quanta/manta" (p.12-13).

A primeira motivação pode ser contestada com uma metáfora da hereditariedlade humana: o fato de o avô de João ter tido olhos azuis não significa necessariamente que João também os tenha. Uma coisa é o avô, outra coisa é João. A segunda motivação também não se sustenta. Muito mais importante do que substituir $/ \mathrm{k}^{\mathrm{w}}, \mathrm{g}^{\mathrm{w}} /$ por consoantes simples ${ }^{6}$ é o fato de esses presumíveis segmentos complexos serem as únicas oclusivas da língua que não admitiriam outra consoante no aclive silábico, como em $/{ }^{*} \mathrm{k}^{\mathrm{w}} \mathrm{rV},{ }^{*} \mathrm{k}^{\mathrm{w}} \mathrm{IV} / \mathrm{e} / \mathrm{g}$ "rV, ${ }^{*} \mathrm{~g}$ [IV/.

Por fim, nas próprias palavras de Garcia transcritas acima, temos um argumento contra sua interpretação e a favor da que proponho aqui. Ao afirmar que $/ \mathrm{k} / \mathrm{e} / \mathrm{g} /$ + u só são segmentos complexos $\left[k^{w}\right]$ e $\left[g^{w}\right]$ quando seguidos de vogal, ela está dando o 
contexto em que isso é previsível. Portanto, sua afirmação equivale a dizer que eles se complexificam por regra, logo, num nível subjacente são /kuV/ e /guV/.

\section{OBSERVAÇÕES FINAIS}

Após as sugestões do(a)s pareceristas anônimo(a)s, conscientizei-me de uma série de problemas que interferem na regra (3) e, mais geralmente, no princípio (4). Um dos contra-exemplos dados por ele(a)s é "cueca". De acordo com a regra (3) essa palavra seria pronunciada ['kwєka], não [ku'عka], como normalmente se diz. Enfim, haveria vários outros contra-exemplos, como "eqüidlade" vs. "acuidade", etc. Porém, o centro de minha argumentação era o de que efetivamente o elemento [w] de [kw] e [gwl pode ser interpretado como variante combinatória de outro fonema. Basta observar pronúncias de formas do verbo "aguar". Creio que ninguém diria "eu ágüo, tu ágüas, ele ágüa, etc.", mas sim "eu agúo, tu agúas, ele agúa, etc.". Muitas gramáticas normativas do português conjugam verbos como "apropinquar" como "eu apropinqúo, tu apropinqúas, etc.". É claro que se alguém conjugar esses verbos com ditongo no final será perfeitamente entendido. Eu só não tenho certeza de que isso seria tido como normal, no sentido de Coseriu (1967).

A reação às vezes até contundente de algum(a)(n)s do(a)s pareceristas mostrou que valeu a pena levantar o problema. Afinal, a própria realidade fonética do português ainda é pouco conhecida. Será que efetivamente dizemos só, e sempre, [ku'eka] e não ['kweka], pelo menos algumas vezes? Será que dizemos só, e sempre, [akuy'dadzil e não, ou também, [akwi'dadzil? Existe ainda o problema adicional da elisão do [w] em muitas ocorrências dos grupos [kw, gw]. Assim, algumas pessoas dizem "sangüíneo", "qüota", "qüotidiano" etc., ao passo que outras dizem "sanguíneo", "cota", "coticliano" e assim por diante (o trema não é necessariamente ortográfico). Quem sabe se de posse de uma descrição bastante 
acurada e detalhada de todas as variedades fonéticas do português poderíamos solucionar a questão definitivamente?

Por fim, gostaria de salientar que este artigo surgiu por influência do trabalho de Leda Bisol, uma das maiores fonólogas do Brasil. Ele mostra o apreço que tenho pela seriedade científica de seu trabalho. Se ele conseguir chamar a atenção para este tópico da fonologia do português, sua vinda a lume estará justificada.

\section{NOTAS}

${ }^{1}$ Em Couto (1994) temos mais exemplos.

${ }^{2}$ Em Bisol (1991:56-57, 1994:), a autora retoma a questão, mantendo a proposta original.

${ }^{3}$ No artigo mencionado na Nota 1, temos exemplos de [kw] e [gw] ocorrendo seguidos de praticamente tockas as vogais da língua portuguesa. Ver também Couto (1996).

${ }^{4}$ Aliás, como já vimos, o status do conceito de fonema na fonologia gerativa não está livre de discordâncias. Na sintaxe nem mesmo a distinção entre estrutura subjacente e estrutura superficial (estrutura fonética, em fonologia) existe mais, com a ressalva de que a fonologia tem uma relativa independência frente à sintaxe.

5 Ver Chomsky (1981) e trabalhos subseqüentes.

"Na verdade, seria melhor contrapor "quanta" a "canta" do que a "manta", e "qual" seria melhor contraposto a "cal", como faz Garcia.

\section{REFERÊNCIAS}

BISOL, Leda. O ditongo na perspectiva da fonologia atual. D.E.L.T.A., 5, 2. p.185-224. 1989.

. O ditongo em português. Boletim da ABRALIN, 11. p.51-58. 1991.

- Ditongos derivados. D.E.L.T.A., v.10, no especial, p.123-140. 1994.

- O sândi e a ressilabação. Com. lida no Seminário Internacional de Fonologia, PUC-RS. 1995.

CHOMSKY, Noam. Principles and parameters in syntactic theory. In: Horstein, N. (Org.) Explorations in linguistics. Londres: Longman: p.32-75. 1981. 
COSERIU, Eugenio. Sistema, norma y habla. In: Teoria del lenguaje y lingüistica general. Madri: Editorial Gredos: 11-113. 1967.

COUTO, Hildo Honório do. Ditongos crescentes e ambissilabicidade em português. Letras de Hoje (PUC-RS). 1994.

Um estudo sobre os ditongos em português. Pesquisa lingüística II (Dpto. de Lingüística, UnB). 1996.

GARCIA, Janete Melasso. Estudo comparativo das estruturas silábicas no latim clássico e no português padrão. Brasília: Universidade de Brasília, 1989. (Dissertação de mestrado).

MARTINS, M. Raquel Delgado. Ouvir falar. Introdução à fonética do português. Lisboa: Caminho, 1988.

PARDAL, Ernesdo d'Andrade. Aspects de la phonologie (générative) du portugais. Lisboa: Centro de Lingüística da Universidade de Lisboa. 1977. 